\title{
Resenha
}

\section{Abordagem epistemológica em um livro-texto sobre mecânica quântica}

\author{
Salomon S. Mizrahi ${ }^{1}$ \\ Departamento de Física, Universidade Federal de São Carlos, São Carlos, SP, Brasil
}

Conceitos de Física Quântica, de Osvaldo Pessoa Jr. (Editora Livraria da Física, São Paulo, 2003), 188 p.

Recentemente fomos brindados com um texto (Volume I) de mecânica quântica (MQ), Conceitos de Física Quântica escrito pelo Prof. Osvaldo Pessoa Jr., e que, em sua página de apresentação, informa que o livro foi elaborado com base na experiência adquirida no decorrer de uma década de cursos ministrados na Universidade de São Paulo e na Universidade Federal da Bahia. Diferentemente dos textos tradicionais de MQ, o livro inova devido à preocupação do autor em apresentar e discutir as várias interpretações da MQ, sem se limitar apenas a discussões sobre epistemologia e linhas filosóficas. Ao longo da maioria dos vinte capítulos encontramos discussões sobre uma variedade de fenômenos quânticos e, quando necessário, o autor faz uso, sem receio, do formalismo matemático da MQ. Os fenômenos são descritos e analisados de acordo com cada uma das interpretações que ele discrimina: ondulatória, corpuscular, dualista realista e da complementaridade.

Em Conceitos de Física Quântica a escolha e a apresentação dos temas diferem, tanto na ordem como na forma, daquelas que encontramos em manuais tradicionais, e.g., Quantum Physics de S. Gasiorowicz (Wiley, New York, 1996) ou Introduction to Quantum Mechanics de R.H. Dicke e J.P. Wittke (AddisonWesley Inc., Reading, MS, USA, 1966). Eu situaria o texto, quanto à escolha e abordagem dos assuntos, numa posição intermediária entre o livro de B. d'Espagnat, Conceptual Foundations of Quantum Mechanics (Addison-Wesley Publhing Company Inc., 1976, 1989) e o Quantum theory: Concepts and Methods (Kluwer Academic Publishers), de A. Peres.

Na Apresentação diz o autor: "O Volume I é uma introdução bastante suave à física quântica, que pode ser aproveitada mesmo por aqueles que nunca cursaram uma disciplina de mecânica quântica, como alunos de

\footnotetext{
${ }^{1}$ E-mail: salomon@df.ufscar.br.

Filosofia, Ensino de Ciências e História da Ciência".

Eu discordo dessa afirmação por diversos motivos, dos quais citarei apenas alguns. No texto são apresentados fenômenos que envolvem experimentos reais ou pensados (gedanken), que fazem uso de interferômetros, polarizadores, prismas, feixes de luz ou de partículas, etc., o que, a meu ver, exigiria de um leitor um razoável conhecimento prévio de óptica ondulatória e uma familiaridade com a álgebra linear para poder entender o tratamento formal de vetores no espaço de Hilbert, o significado de superposição e rotação de vetores, etc. Muitos assuntos discutidos contêm sutilezas próprias da teoria e que mereceriam uma maior reflexão por parte do autor. Por exemplo, (1) na página 46, terceiro parágrafo, é dito que a equação de Schrödinger (ES) descreve sistemas fechados englobando duas situações: sistemas isolados (o operador hamiltoniano não tem dependência explícita do tempo - a energia média é conservada) e sistemas sujeitos a campos externos bem determinados que não reagem nas entidades físicas que criam os campos (presença no hamiltoniano com um termo de energia potencial dependente do tempo - a energia média não é conservada). Entretanto, para muitos sistemas descritos por hamiltonianos dependentes do tempo, pode-se encontrar um novo referencial (transformação unitária dependente do tempo) que leve a uma outra ES cujo hamiltoniano não apresenta mais dependência temporal explícita, e portanto, o sistema parecerá um sistema isolado quando "visto" no novo referencial. Logo, dizer que um sistema é isolado ou não irá depender do referencial adotado. (2) Na página 88 encontra-se uma discussão sobre o "operador fase", um assunto polêmico, pois sua existência e definição são ainda hoje bastante controversas; en passant, aproveito para alertar que o acento circunflexo deveria cobrir os objetos sen $\Phi$ e e $\cos \Phi$, que são símbolos, pois eles não representam as operações vulgares de seno e co-seno.

Um leitor pouco familiarizado com as nuances, sutilezas e "paradoxos" da MQ poderá encontrar dificul- 
dades em acompanhar os conceitos e discussões do livro, mas para que ele não se sinta pouco capacitado cito A.J. Leggett $^{2}$, físico laureado com o prêmio Nobel de Física de 2003: a Mecânica Quântica é muito mais do que apenas uma teoria; é uma forma totalmente nova de olhar para o mundo, envolvendo uma mudança no paradigma, talvez mais radical que qualquer outro na história do pensamento humano. Portanto, com a MQ criou-se um plano de clivagem entre o pensamento tradicional da Física (incluindo-se aí a teoria da relatividade) e o novo pensamento; sua interpretação exige um despojamento de conceitos tradicionais como, trajetória, localização, etc.... e a assimilação de novos como, amplitude de probabilidade, não-localidade, inseparabilidade, indistinguibilidade de partículas, decoerência e outros mais.

Embora, com o seu conjunto de postulados e teoremas, (na sua estrutura formal), a MQ não apresenta inconsistências ou paradoxos, a tempestade criada pelo estudo epistemológico desde sua invenção ainda não amainou totalmente. Para físicos como A. Peres, M. Gell-Mann, N.G. van Kampen e outros, a MQ é um conjunto de regras que permite fazer previsões acerca de fenômenos físicos passíveis de medição. Esse pensamento utilitarista da MQ não exclui a prática interpretativa, mas seus adeptos não se aborrecem com a inexistência de uma interpretação única e não ambígua. Por exemplo, um tópico bastante bem discutido pelo autor é a chamada teoria da medição, onde o choque com o pensamento clássico é mais marcante. O desconforto surge com o postulado da projeção: quando é feita a medição de uma propriedade de um sistema, o seu vetor de estado reduz-se "subitamente" a um dos muitos possíveis autoestados. Embora esse "colapso" ocorre de maneira aleatória, repetindo-se o processo de medição - sob as mesmas condições - muitas e muitas vezes, o experimentador conseguirá obter a distribuição estatística dos valores medidos, que ele associará ao estado (de pré-medição) do sistema. Enquanto a epistemologia procura uma explicação para os súbitos "colapsos", os utilitaristas vêem isso como uma das regras da MQ, sem encontrar necessidade para um maior aprofundamento. Via de regra, os homens e mulheres de ciência têm feito uso do receituário formal da MQ sem demasiada preocupação em analisar o resultados dos seus cálculos à luz (ou à sombra?) das diversas interpretações existentes.

O livro de Osvaldo Pessoa Jr. vem complementar a literatura existente sobre MQ, é um livro não trivial, pois as interpretações da MQ são bastante controversas e elas exigem do leitor um pensamento treinado e uma familiaridade com o arcabouço da física teórica. De todo modo, é um livro que merece ser lido e discutido pelos físicos (pelo menos daqueles que ministram cursos de MQ), visto que, se aceitamos as conjecturas do filósofo K. Popper, em algum momento a teoria quântica poderá ser refutada e substituída por outra mais abrangente e com menos interpretações polêmicas. E para esse momento os físicos precisarão estar preparados para entender e participar dessa (possível, mas, que acredito, pouco provável) revolução.

Encontramos uma bibliografia abrangente com referências distribuídas ao longo do texto e seu capítulo final apresenta uma coleção de problemas e um questionário lúdico. Finalmente, quiçá o capítulo XIV, Realismo e positivismo, deveria anteceder os demais, para melhor instruir o leitor antes de iniciar as discussões sobre as várias interpretações da MQ.

\footnotetext{
${ }^{2}$ Testing the limits of quantum mechanics: Motivation, state of play, prospects, J. Phys.: Condens. Matter 14, R415-R451, (2002).
} 